\title{
Motivos que justificam a adesão de adolescentes à prática da natação: qual o espaço ocupado pela saúde?
}

\author{
Mariana Pace Alves ${ }^{1}$, Washington Leite Junger ${ }^{2}$, Alexandre Palma ${ }^{1}$, Walace David Monteiro ${ }^{3-4}$ \\ e Helder Guerra de Resende ${ }^{1}$
}

\section{RESUMO}

Acredita-se que um dos principais motivos para a adesão à prática da natação sejam os relacionados à saúde. Contudo, a literatura é carente de estudos que confrontam a incidência da saúde com outros motivos que podem justificar a adesão à prática da natação. Considerando este contexto, o presente estudo teve como objetivo identificar os principais motivos que influenciam os adolescentes a iniciar e a permanecer praticando natação, situando o papel da saúde neste contexto. A amostra foi composta por 98 adolescentes não atletas de ambos os sexos, com idades entre 13 e 18 anos. Foi construído um instrumento de coleta de dados composto por questões objetivas de caracterização do respondente, além de uma escala de opinião sobre os motivos que influenciam adolescentes a permanecer praticando natação. O estudo foi desenvolvido em três estabelecimentos de ensinoaprendizagem de natação no município do Rio de Janeiro. Para verificar a confiabilidade do instrumento de coleta de dados foi utilizado o Coeficiente Alfa, enquanto que para a análise dos dados utilizou-se recursos da estatística descritiva (média, desviopadrão e percentual) e inferencial (ANOVA - $p<0,05$ ). Os resultados revelaram que os motivos relacionados à saúde correspondem a $13 \%$ do total. Já a escala de opinião utilizada para verificar os motivos de permanência revelou que as categorias relacionadas à saúde que obtiveram maiores médias de pontuação, numa escala de até 2 pontos, foram: bem-estar $(1,86)$; condicionamento físico $(1,70)$ e prevenção de doença $(1,62)$. A ANOVA não detectou diferenças nas respostas ao questionário atribuídas pelos indivíduos dos dois sexos. Em conclusão, ao menos na amostra estudada, o fator saúde não exerce um peso acentuado na opção de adolescentes para iniciar um programa de natação. Entretanto, motivos relacionados à saúde vão ganhando importância, constituindo-se num dos principais fatores que justificam a permanência dos indivíduos nos programas de natação.

\section{ABSTRACT \\ Reasons which justify the engagement of adolescents in swimming practice: what is health importance?}

It is believed that one of the main reasons for the engagement in swimming practice is health-related. However, the literature is scarce on studies which compare the incidence of health with other reasons which may justify the engagement in swimming practice. Within this context, the present study had the aim to

1. Programa de Pós-graduação Stricto Sensu em Educação Física, Universidade Gama Filho.

2. Instituto de Medicina Social, Universidade do Estado do Rio de Janeiro.

3. Programa de Pós-graduação Stricto Sensu em Ciências da Atividade Física, Universidade Salgado de Oliveira.

4. Laboratório de Atividade Física e Promoção da Saúde, Universidade do Estado do Rio de Janeiro.

Aceito em 3/7/07.

Endereço para correspondência: Helder Guerra de Resende, Rua Manoel Vitorino, 625 - 20748-900 - Rio de Janeiro, RJ. E-mail: ppgef@ugf.br

\author{
Palavras-chave: Promoção da saúde. Adesão. Natação. Adolescentes. \\ Keywords: Health promotion. Engagement. Swimming. Adolescents.
}

identify the main reasons which influence adolescents in initiating as well as continuing to practice swimming, placing the role of health in this context. The sample consisted of 98 non-athlete adolescents of both sexes, with age range from 13 and 18 years. A data collection instrument composed of objective questions of characterization of the interviewees was built; besides an opinion scale on the reasons which have influenced adolescents to keep on swimming. The study was developed in three teaching-learning swimming environments in the city of Rio de Janeiro. The Alpha coefficient has been used to verify the reliability of the data collection instrument, while descriptive statistical analysis (mean, standard deviation and percentage) and inferential (ANOVA - $p<$ $0.05)$ resources have been used for the data analysis. The outcomes revealed that the health-related reasons correspond to $13 \%$ of the total. The opinion scale used to verify the reasons for remaining, revealed that the categories concerned with health which had the highest punctuation means in a scale up to two points, were: well-being (1.86); physical fitness (1.70) and disease prevention (1.62). ANOVA did not detect differences in the answers to the questionnaire given by the individuals of both sexes. As a conclusion, at least in the studied sample, health is not a crucial element in adolescents' choice in order to engage in a swimming program. However, health-related reasons have become more important and are one of the main reasons which justify the continuous engagement of individuals in swimming programs.

\section{INTRODUÇÃO}

A literatura tem destacado que a prática regular de exercícios físicos atua na prevenção de diversas doenças como o diabetes, a hipertensão, a osteoporose, o câncer de colo, a doença arterial coronariana e a obesidade, entre outras ${ }^{(1-2)}$. Além disso, a prática de exercícios físicos pode contribuir também para prevenir a incidência da obesidade infantil(3), assim como, favorecer o aumento da densidade óssea em crianças e adolescentes ${ }^{(4)}$. Especificamente no caso da natação, tem sido difundido que sua prática regular pode ser importante também na ajuda ao tratamento da asma em crianças ${ }^{(5-6)}$

Alguns autores destacam que a prática de exercício físico na infância facilita a adesão a esse comportamento na vida adulta (7-8). A quantidade e a qualidade das aulas de educação física na escola, a participação em programas esportivos fora do ambiente escolar, a indicação médica, o incentivo dos pais são alguns aspectos ocorridos no período da infância que podem influenciar a adesão à prática de exercício físico na vida adulta(9).

No Brasil ainda são escassos os estudos que acompanham o envolvimento da população com a prática regular de exercícios físicos, o que dificulta inferências consistentes sobre o assunto. Entretanto, o número de indivíduos interessados ou levados por algum tipo de necessidade a praticar exercícios físicos regularmente parece estar aumentando. A literatura revela que esta proporção ainda é baixa em relação aos não praticantes, e que pou- 
cos permanecem motivados e engajados em um programa de exercício físico por longo período de tempo. Alguns indivíduos interrompem por um determinado período e depois retornam, enquanto outros abandonam definitivamente ${ }^{(10)}$.

Programas relacionados à educação e à promoção da saúde, nas perspectivas da prevenção primária ou de modelos de capacitação, têm-se tornado foco crescente de investimentos e de intervenções decorrentes de políticas públicas de diversos países. Este movimento transcultural e de dimensão internacional reconhece o caráter plurifatorial da saúde ${ }^{(11)}$, demandando que a intervenção não considere somente as mudanças individuais de comportamento, mas também modificações relacionadas às questões educacionais, de saneamento e de acesso aos serviços de saúde, entre outros aspectos ${ }^{(12)}$. Por outro lado, os programas direcionados a promoção de exercícios físicos e a prevenção de doenças têm como principal argumento o fato do sedentarismo ser um importante fator de risco, associado ao surgimento e agravamento de doenças crônico-degenerativas ${ }^{(2)}$

Este cenário tem incentivado estudos para identificar as barreiras enfrentadas pelas pessoas para não praticarem exercícios físicos, bem como os principais fatores que podem influenciá-los a iniciar, a permanecer ou a abandonar a prática de exercícios físi$\cos ^{(13)}$. No Brasil, a realização de estudos dessa natureza é recente e poucos se referem especificamente à natação. Os tópicos mais abordados relacionam-se às técnicas dos quatro estilos oficiais, ao treinamento físico, às respostas fisiológicas, à biomecânica dos estilos, às metodologias de ensino-aprendizagem e às contribuições da prática da natação para o desenvolvimento motor $^{(14)}$. Neste contexto, o objetivo deste trabalho foi identificar os principais motivos que influenciam os adolescentes a iniciar e a permanecer praticando natação, situando o papel da saúde neste contexto.

\section{MÉTODOS}

\section{Amostra}

Participaram do estudo 98 indivíduos $(67$ homens e 32 mulheres), com idades entre 13 e 18 anos $(14,7 \pm 1,6)$, matriculados em três escolas de natação situadas no município do Rio de Janeiro. Foi utilizada uma amostragem não-probabílistica por conveniência. As escolas foram escolhidas por representarem estabelecimentos de ensino-aprendizagem da natação que privilegiam a possibilidade de aprendizagem e prática continuada a diferentes demandas motivacionais, incluindo aprendizagem utilitária, lazer, saúde e terapêutica, independentemente da faixa etária e da situação socioeconômica. Antes da coleta de dados todos os voluntários assinaram um termo de consentimento pós-informado, conforme resolução do Conselho Nacional de Saúde (196/96).

\section{Protocolo}

Para identificar os principais motivos que levam os adolescentes a iniciar e permanecer praticando natação, foi construído um instrumento para coleta de dados, tendo como base a literatura sobre fatores e motivos que influenciam adolescentes a aderir aos programas de exercícios físicos ${ }^{(15-16)}$. O desenvolvimento do instrumento deveu-se ao fato de que os já existentes na literatura ${ }^{(17-19)}$ não contemplam alguns motivos importantes, tais como metodologia empregada de ensino-aprendizagem, empatia com o professor e ambiente físico. Também considerou-se apropriado desenvolver um instrumento específico para investigar a população alvo, composta por jovens brasileiros não-atletas praticantes de natação.

O instrumento foi composto por duas partes (anexo 1). A primeira envolveu um questionário composto por perguntas objetivas com a finalidade de identificar as características do grupo investigado, além de uma pergunta para identificar os motivos que influenciaram os adolescentes a iniciar a prática da natação. Nesta pergunta, o informante tinha 16 opções de motivos para assinalar, sendo permitido indicar, por ordem de importância, no máximo três motivos. Outros motivos podiam ser acrescentados, caso não estivessem contemplados nas opções listadas.

A segunda parte do instrumento foi constituída por uma escala de opinião, composta de 40 itens agrupados em 17 categorias, para avaliar os motivos alegados pelo grupo para permanecer praticando natação. Cada informante foi orientado a ler cada frase e assinalar a opção que melhor representava o grau de importância do item para ele permanecer praticando natação, a saber: a) não importante; b) mais ou menos importante; c) muito importante. Um escore foi definido como a média de pontos de cada categoria, de acordo com a seguinte escala de valores: 0 (zero) quando o informante indicou que o motivo era 'nada importante'; 1 ponto quando o motivo foi considerado 'mais ou menos importante'; e 2 pontos para 'muito importante'.

Os motivos agrupados em 17 categorias foram: diversão, desafio, bem-estar pessoal, relacionamento social, prevenção de doenças, atividade terapêutica, estética corporal, condicionamento físico, reconhecimento social, rendimento esportivo, influência de terceiros, ambiente físico, facilidade de horário e de acesso ao local de prática, características específicas do tipo de exercício físico, custo, metodologia de ensino-aprendizagem e empatia com o professor. Estas categorias foram validadas qualitativamente por uma banca composta por três especialistas. Alguns itens já validados nos instrumentos consagrados foram mantidos e outros propostos de acordo com os especialistas, após a realização de três rodadas de discussão, cujo objetivo foi assegurar a adequada caracterização de cada categoria em função dos respectivos indicadores comportamentais.

Antes da coleta de dados, realizou-se um estudo piloto para avaliar a adequação da linguagem e da estrutura do instrumento à população alvo, contatando-se que os informantes não apresentaram dificuldades para compreender e para preencher o questionário. Para tanto, um grupo de 40 adolescentes com características semelhantes às da população alvo deste trabalho responderam ao instrumento.

\section{Tratamento estatístico}

Com intuito de verificar a confiabilidade do instrumento foi utilizado o Alfa de Cronbach(20). Para identificar os motivos alegados para ingressar em programas de natação foi realizado o cálculo percentual das respostas assinaladas no questionário. A análise dos principais motivos alegados para permanecerem praticando natação foi realizada a partir do cálculo de médias, obtidas a partir das categorias que compuseram a escala de opiniões (pontuação de 0 a 2). Por fim, para verificar se os resultados da escala de opinião se diferenciavam por sexo, utilizou-se a ANOVA de uma entrada, considerando o nível de significância de 5\%.

\section{RESULTADOS}

A confiabilidade da escala de opinião apresentou um Coeficiente Alfa de Cronbach de 0,88, o que indica a existência de consistência interna entre as categorias do instrumento. Este resultado indica que o instrumento de coleta de dados apresenta um índice satisfatório de confiabilidade.

Em relação aos motivos que influenciaram o grupo investigado a iniciar a prática da natação, a soma dos pontos obtidos em cada item revelou que os principais motivos foram decorrentes de aspectos motivacionais de ordem intrínseca e extrínseca, a saber: 'porque eu sempre gostei de fazer natação' (16,04\%), 'porque meus pais ou responsáveis decidiram que era importante eu praticar natação' (14,95\%), 'porque o médico me aconselhou' $(12,97 \%)$, 'para melhorar meu condicionamento físico' $(10,45 \%)$ e 'porque eu não sabia nadar' $(10,27 \%)$. Juntos estes motivos re- 
TABELA 1

Principais motivos alegados pelos adolescentes para iniciar a prática da natação

\begin{tabular}{|c|c|c|c|c|c|c|}
\hline \multirow[t]{2}{*}{ Motivos } & \multicolumn{2}{|c|}{$\begin{array}{l}\text { Adolescentes de } \\
\text { ambos os sexos }\end{array}$} & \multicolumn{2}{|c|}{$\begin{array}{l}\text { Adolescentes do } \\
\text { sexo masculino }\end{array}$} & \multicolumn{2}{|c|}{$\begin{array}{l}\text { Adolescentes do } \\
\text { sexo feminino }\end{array}$} \\
\hline & Pontos & $\%$ & Pontos & $\%$ & Pontos & $\%$ \\
\hline Porque eu sempre gostei de fazer natação & 89 & 16,04 & 52 & 13,68 & 37 & 21,14 \\
\hline $\begin{array}{l}\text { Porque meus pais ou responsáveis decidiram } \\
\text { que era importante eu praticar natação }\end{array}$ & 83 & 14,95 & 66 & 17,37 & 17 & 9,71 \\
\hline Porque o médico me aconselhou & 72 & 12,97 & 42 & 11,05 & 30 & 17,14 \\
\hline Para melhorar meu condicionamento físico & 58 & 10,45 & 43 & 11,32 & 15 & 8,57 \\
\hline Porque eu não sabia nadar & 57 & 10,27 & 41 & 10,79 & 16 & 9,14 \\
\hline Para evitar problemas de saúde & 45 & 8,11 & 29 & 7,63 & 16 & 9,14 \\
\hline Porque eu queria ter um corpo bonito & 31 & 5,59 & 23 & 6,05 & 8 & 4,57 \\
\hline Porque eu queria ou precisava emagrecer & 26 & 4,68 & 16 & 4,21 & 10 & 5,71 \\
\hline $\begin{array}{l}\text { Porque eu queria me sentir bem físico } \\
\text { e emocionalmente }\end{array}$ & 24 & 4,32 & 15 & 3,95 & 9 & 5,14 \\
\hline Porque eu queria ser um atleta de natação & 22 & 3,96 & 19 & 5,00 & 3 & 1,71 \\
\hline $\begin{array}{l}\text { Pela possibilidade de estar em companhia } \\
\text { dos meus amigos e fazer novas amizades }\end{array}$ & 13 & 2,34 & 10 & 2,63 & 3 & 1,71 \\
\hline $\begin{array}{l}\text { Porque eu queria aprender uma nova } \\
\text { atividade física }\end{array}$ & 13 & 2,34 & 8 & 2,11 & 5 & 2,86 \\
\hline $\begin{array}{l}\text { Porque a natação é um tipo de atividade } \\
\text { física que possibilita diferentes desafios }\end{array}$ & 10 & 1,80 & 6 & 1,58 & 4 & 2,29 \\
\hline $\begin{array}{l}\text { Porque era a única atividade que tinha perto } \\
\text { da minha casa/local de trabalho/local de estudo }\end{array}$ & 7 & 1,26 & 6 & 1,58 & 1 & 0,57 \\
\hline $\begin{array}{l}\text { Porque a mensalidade era mais adequada às } \\
\text { minhas possibilidades de pagamento (ou se } \\
\text { for o caso, dos meus pais e responsáveis) }\end{array}$ & 2 & 0,36 & 2 & 0,53 & 0 & - \\
\hline $\begin{array}{l}\text { Porque as pessoas que praticam natação } \\
\text { são mais valorizadas }\end{array}$ & 1 & 0,18 & 1 & 0,26 & 0 & - \\
\hline Outros* & 2 & 0,36 & 1 & 0,26 & 1 & 0,57 \\
\hline Total & 555 & 100 & 380 & 100 & 175 & 100 \\
\hline
\end{tabular}

* Os motivos indicados foram: 'para surfar melhor' e 'para prestar um concurso'.

TABELA 2

Média de pontuação das categorias

\section{Categorias}

Bem-estar pessoal

Condicionamento físico

Prevenção de doenças

Diversão

Empatia com o professor

Características específicas do tipo de atividade física

Facilidade de horário e acesso ao local de prática

Relacionamento social

Metodologia de trabalho

Estética corporal

Desafio

Custo

Reconhecimento socia

Rendimento esportivo

Ambiente físico

Atividade terapêutica
Influência de terceiros

\begin{tabular}{ccc}
$\mathbf{n}$ & Média & $\begin{array}{c}\text { Desvio- } \\
\text { padrão }\end{array}$ \\
98 & 1,867 & 0,348 \\
98 & 1,704 & 0,403 \\
98 & 1,622 & 0,561 \\
96 & 1,572 & 0,526 \\
96 & 1,559 & 0,449 \\
98 & 1,285 & 0,542 \\
98 & 1,285 & 0,511 \\
96 & 1,234 & 0,593 \\
98 & 1,227 & 0,460 \\
96 & 1,208 & 0,635 \\
95 & 1,052 & 0,585 \\
98 & 1,020 & 0,710 \\
96 & 0,901 & 0,618 \\
96 & 0,880 & 0,717 \\
96 & 0,875 & 0,670 \\
98 & 0,872 & 0,584 \\
96 & 0,656 & 0,765 \\
\hline & &
\end{tabular}

presentaram $64,68 \%$ do total de pontos obtidos nas respostas. A diferenciação dos resultados do grupo como um todo e distinto por sexo são verificados na tabela 1.

Os motivos que influenciaram o grupo investigado a permanecer praticando natação são ilustrados na tabela 2. Como pode ser

\begin{tabular}{|c|c|c|c|c|c|c|c|c|}
\hline $\begin{array}{r}\text { Resulta } \\
\text { motivos q }\end{array}$ & $\begin{array}{l}\text { os di } \\
\text { e jus }\end{array}$ & $\begin{array}{l}\text { TA } \\
\text { istintos } \\
\text { stifican }\end{array}$ & $\begin{array}{l}\text { BELA } \\
\text { por se } \\
\text { a per }\end{array}$ & $\begin{array}{l}\text { o, er } \\
\text { anê }\end{array}$ & $\begin{array}{l}\mathrm{m} \text { relaç } \\
\text { ncia na }\end{array}$ & $\begin{array}{l}\text { ão aos } \\
\text { nataçã }\end{array}$ & & \\
\hline Categorias & & Masculi & ino & & Femini & ino & $\mathbf{F}$ & Valor $\mathrm{P}$ \\
\hline & $\mathbf{n}$ & Média & Dp & $\mathbf{n}$ & Média & Dp & & \\
\hline Bem-estar pessoal & 67 & 1,881 & 0,349 & 31 & 1,839 & 0,351 & 0,304 & 0,583 \\
\hline Condicionamento físico & 67 & 1,692 & 0,420 & 31 & 1,731 & 0,369 & 0,203 & 0,653 \\
\hline Prevenção de doenças & 67 & 1,597 & 0,592 & 31 & 1,677 & 0,492 & 0,433 & 0,512 \\
\hline Diversão & 65 & 1,610 & 0,519 & 31 & 1,495 & 0,544 & 1,011 & 0,317 \\
\hline Empatia com o professor & 65 & 1,554 & 0,472 & 31 & 1,570 & 0,406 & 0,026 & 0,871 \\
\hline
\end{tabular}

observado, os jovens justificaram a manutenção da prática da natação com base em argumentos identificados com o 'bem-estar pessoal', o 'condicionamento físico', a 'prevenção de doenças', a 'diversão' e a 'empatia com o professor'. Estas foram as categorias que obtiveram os maiores escores (superiores a 1,5).

A fim de verificar se os principais motivos que influenciam os adolescentes a permanecer praticando natação são diferenciados por sexo, analisaram-se apenas as categorias que alcançaram escores acima de 1,5: 'bem-estar pessoal', 'condicionamento físico', 'prevenção de doenças', 'diversão' e 'empatia com o professor'. Neste caso, não foram encontradas diferenças significativas entre os escores dos dois grupos (tabela 3), o que sugere que estes motivos foram valorizados de forma semelhante pelos informantes de ambos os sexos. 


\section{DISCUSSÃO}

Em função dos resultados obtidos, foi possível identificar o conjunto de motivos que influenciam os adolescentes a iniciar e a permanecer praticando natação. Fato relevante refere-se à natureza dos motivos alegados pelos informantes para iniciar a prática da natação que obtiveram maior incidência de pontuação. Recorreu-se às categorias explicativas da conduta humana sugerida por Lovisolo(21) para inferir que os principais motivos indicados contemplaram as três dimensões abordadas pelo autor: a norma ('porque meus pais ou responsáveis decidiram que era importante eu praticar natação'), a utilidade ('porque eu não sabia nadar', 'para melhorar meu condicionamento físico' e 'porque o médico me aconselhou') e o gosto ('porque eu sempre gostei de fazer natação'). É interessante ressaltar que esses motivos não se limitaram apenas a uma das categorias motivacionais referidas por Lovisolo.

Este estudo apresenta resultados semelhantes aos revelados em investigações realizadas com jovens, focalizando outros programas de exercícios físicos. Santos e Barcelos ${ }^{(22)}$, por exemplo, verificaram por meio de um questionário preenchido por 17 atletas com idade média de 18 anos, de uma equipe masculina de handebol, que $41 \%$ dos sujeitos iniciaram a prática do esporte por influência de amigos, 24\% por lazer, 23\% por curiosidade e 12\% por influência da mídia.

Em condições semelhantes, Botti e Vieira(23), em uma pesquisa realizada com 10 atletas de ginástica rítmica desportiva da seleção brasileira juvenil, constataram que a maioria iniciou a prática desse esporte por influência de amigas. De fato, a literatura indica que o apoio e o incentivo de companheiros, familiares e amigos influenciam a adesão de crianças e de adolescentes a programas de exercícios físicos ${ }^{(8-9,16,24)}$.

Estudos que investigaram outros grupos etários constataram que os motivos relacionados à saúde são freqüentemente mencionados nas pesquisas. Costa(25), por exemplo, verificou que o interesse em conquistar e/ou preservar a saúde foi o principal motivo que levou 64 indivíduos, de ambos os sexos, com idades entre 16 e 60 anos, a ingressar em aulas de natação em academias. Benassi e Shigunov ${ }^{(26)}$ analisaram os motivos que influenciaram 137 sujeitos, de ambos os sexos, com idade superior a nove anos, a iniciar a prática da natação, constatando que os mais indicados para a prática da natação foram os relacionados à saúde e ao bem-estar (71,2\% das respostas).

Vieira e Ferreira(27), por sua vez, ao investigarem o perfil de 289 indivíduos de ambos os sexos com idade superior a 15 anos que praticam atividades físicas na pista do estádio do Maracanã (Rio de Janeiro), observaram um percentual maior de informantes $(72,3 \%)$ que começaram a praticar exercícios físicos por motivos relacionados à saúde. Este percentual é semelhante ao revelado pela pesquisa de Benassi e Shigunov ${ }^{(27)}$ com praticantes de natação $(71,2 \%)$. Outros motivos também identificados pelos pesquisadores foram os relacionados à estética corporal e ao lazer.

Com relação aos motivos alegados pelos jovens no presente estudo para permanecer praticando natação, não foi possível comparar os resultados com outros trabalhos devido à sua escassez. No entanto, analisando os estudos que investigaram a permanência de outros grupos etários em diversos tipos de exercícios físicos, verificaram-se algumas semelhanças nos resultados encontrados. Cid (28), por exemplo, ao pesquisar os motivos alegados por 110 indivíduos do sexo masculino, entre 15 e 20 anos, para praticarem diferentes tipos de exercícios físicos, verificou que os principais motivos foram "manter a forma", "estar em boa condição física", "prazer" e "divertimento". Outro estudo, envolvendo crianças, adolescentes, adultos e idosos identificou o "lazer", a "diversão" e a "estética" como os principais motivos apontados pelas pessoas para praticarem exercícios físicos ${ }^{(29)}$. Scalon(30), por sua vez, ao investigar 119 crianças, entre 9 e 12 anos de idade, cons- tatou que elas praticavam exercícios físicos por "gostar de estar alegre e se divertir", "gostar de melhorar suas habilidades", "gostar de encontrar novos amigos" e "gostar de esporte em equipes". Nestes estudos chama atenção o fato dos aspectos associados à saúde não serem preponderantes em relação a outras categorias de motivos justificadores da adesão à prática de exercícios físicos.

No entanto, recente pesquisa desenvolvida por Castro(31) aponta resultados diferenciados em relação ao encontrado na literatura. Pesquisando um grupo de 986 pessoas entre 15 e 60 anos, constatou que motivos relacionados à saúde são importantes indicativos para iniciar a prática de diferentes atividades físico-esportivas, não sendo, no entanto, de fundamental importância para a manutenção da prática. Cabe ressaltar que estes dados são opostos aos encontrados no presente estudo, mostrando que a especificidade populacional pode diferir sobremaneira, influenciando os motivos de adesão à prática de exercícios. Outro fator que pode explicar as diferenças de resultados destes estudos refere-se à crescente associação da prática de atividades físico-esportivas com motivos relacionados ao lazer, à diversão.

É relevante ressaltar que os motivos relacionados à categoria 'afinidade com o professor', constatado no presente estudo, ainda não tinham sido identificados em pesquisas sobre a permanência dos adolescentes em programas de exercícios físicos. Com respeito a esse aspecto, Andreoti(32), ao analisar os fatores que influenciaram um grupo de 41 idosos a permanecer em um programa de exercício físico, verificou que a relação estabelecida com os professores foi um fator importante para os indivíduos continuarem participando do programa. Outros fatores constatados pela pesquisadora foram a 'relação estabelecida com os alunos', as 'características educacionais do programa' e os 'benefícios relacionados à saúde'. Isso mostra que a prescrição de exercícios, por envolver aspectos pedagógicos além dos fisiológicos, relacionase à didática do professor para organizar e passar os conteúdos das aulas.

É possível inferir que existem algumas semelhanças nos resultados revelados nas investigações que diagnosticaram os principais motivos que influenciam os indivíduos a ingressar e a permanecer em programas de exercícios físicos. Verifica-se, no entanto, que os motivos relacionados à saúde ainda são citados freqüentemente pelos indivíduos tanto para iniciar quanto para permanecer na prática regular de um exercício físico.

No entanto, os estudos já realizados ainda não são conclusivos e generalizáveis. Isto pode ser decorrente dos diferentes aspectos metodológicos que orientam a realização das pesquisas sobre o tema da adesão aos exercícios físicos. Entre eles pode-se citar a especificidade e a representatividade populacional, os diferentes tipos de instrumentos de coleta de dados, as análises estatísticas realizadas, entre outros motivos.

O presente estudo permitiu concluir que o fator saúde não exerce um peso acentuado na opção de adolescentes em iniciar um programa de natação, enquanto que esse fator ganha maior importância para a permanência. É evidente a necessidade de realização de novos estudos dessa natureza, envolvendo outras faixas etárias, tipos de exercícios físicos, locais de prática, bem como grupos com características diferentes das apresentadas neste estudo. É necessária também a realização de outros trabalhos que avaliem os motivos que levam os indivíduos a interromper e abandonar em definitivo a prática de exercícios físicos. Isto porque, identificar as barreiras e as restrições alegadas pelas pessoas para não se exercitarem pode contribuir para a elaboração de políticas públicas e programas que visem melhorar a qualidade de vida, o bem-estar e a saúde das populações.

Todos os autores declararam não haver qualquer potencial conflito de interesses referente a este artigo. 
ANEXO 1

Instrumento de Diagnóstico da Adesão à Prática da Natação (IDAPRAN)

1. Sexo

( ) masculino

( ) feminino

2. Quantos anos você tem?

anos.

3. Quantos anos você tinha quando começou a fazer aulas de natação?

( ) Até 6 anos.

( ) De 7 a 12 anos.

( ) De 13 a 19 anos

4. Há quanto tempo, mais ou menos, você pratica natação?

( ) 6 meses ou menos.

( ) mais de 6 meses.

5. Antes de você começar a nadar, você praticava outra(s) atividade(s) física(s)?

( ) praticava, porém não regularmente.

( ) praticava regularmente.

( ) não praticava.

( ) não me lembro.

Caso afirmativo, escreva qual ou quais atividade(s) física(s) você praticava?

6. Atualmente, você pratica outra(s) atividade(s) física(s), além da natação?

( ) pratico, porém não regularmente

( ) pratico regularmente.

( ) não pratico.

Caso afirmativo, escreva qual ou quais atividade(s) física(s) você pratica atualmente, além da natação?

7. Assinale a afirmação que melhor representa o seu caso:

( ) dependo da companhia de alguém para ir à natação.

( ) não dependo da companhia de alguém para ir à natação.

8. Como você vai para a natação?

( ) de carro.

( ) de ônibus.

( ) andando.

( ) de bicicleta.

Escreva outra resposta se o seu caso for diferente das afirmações acima:

9. O lugar onde você pratica natação é...

( ) muito longe de casa.

( ) longe de casa.

( ) perto de casa.

( ) muito perto de casa.

10. Atualmente, quantas vezes por semana você pratica natação:

( ) uma vez.

( ) duas vezes.

( ) três vezes.

( ) mais de três vezes.

11. Quais os principais motivos que te levaram a praticar natacão (escolha no máximo três motivos, colocando o número "1" para o principal motivo, "2" para o segundo motivo em ordem de importância, e "3" para o terceiro principal motivo.

Eu comecei a praticar natação (...)

( ) porque era a única atividade física que tinha perto da minha casa/local de trabalho/local de estudo.

( ) porque meus pais ou responsáveis decidiram que era importante eu praticar natação.

( ) porque o médico me aconselhou.

( ) porque eu não sabia nadar.

( ) porque eu queria ser um atleta de natação.

( ) porque eu queria ter um corpo bonito.

( ) porque eu queria ou precisava emagrecer.

( ) para melhorar meu condicionamento físico (eu vivia cansado ou me cansava facilmente).

( ) porque eu sempre gostei de fazer natação.

( ) pela possibilidade de estar em companhia dos meus amigos e fazer novas amizades.

( ) porque a mensalidade era mais adequadas às minhas possibilidades de pagamento (ou, se for o caso, dos meus pais ou responsáveis).

( ) para evitar problemas de saúde.

( ) porque eu queria aprender uma nova atividade física.

( ) porque as pessoas que praticam natação são mais valorizadas.

( ) porque a natação é um tipo de atividade física que possibilita diferentes desafios.

( ) porque eu queria me sentir bem físico e emocionalmente.

Escreva outro(s) motivo(s) se o seu caso for diferente das afirmações acima:

12. Atualmente, você participa de competição oficiais da federação de natação na condição de atleta?

( ) $\operatorname{sim}$.

( ) não.

A seguir, listamos várias frases que as pessoas, geralmente, respondem para justificar o porquê continuam praticando uma determinada atividade física. Leia atentamente cada uma das frases e assinale o nível de importância que cada uma delas tem para justificar o porquê você continua praticando natação.

\begin{tabular}{|c|c|c|c|}
\hline $\begin{array}{l}\text { Eu continuo praticando } \\
\text { natação porque }(. . .)\end{array}$ & $\begin{array}{l}\text { Muito } \\
\text { importante }\end{array}$ & $\begin{array}{c}\text { Mais ou } \\
\text { menos } \\
\text { importante }\end{array}$ & $\begin{array}{l}\text { Nada } \\
\text { importante }\end{array}$ \\
\hline \multicolumn{4}{|l|}{ a temperatura da água é agradável } \\
\hline \multicolumn{4}{|l|}{ as aulas são bem organizadas } \\
\hline \multicolumn{4}{|l|}{ deixa o corpo 'sarado' } \\
\hline \multicolumn{4}{|l|}{ quero ser um atleta } \\
\hline \multicolumn{4}{|l|}{ é muito desafiante } \\
\hline \multicolumn{4}{|c|}{$\begin{array}{l}\text { é uma atividade física que proporciona } \\
\text { situações desafiantes }\end{array}$} \\
\hline \multicolumn{4}{|l|}{ é uma atividade física saudável } \\
\hline \multicolumn{4}{|l|}{ eu adoro fazer atividades na água } \\
\hline \multicolumn{4}{|l|}{ eu fico mais resistente, forte e veloz } \\
\hline \multicolumn{4}{|l|}{$\begin{array}{l}\text { eu utilizo recursos e materiais legais } \\
\text { durante as aulas }\end{array}$} \\
\hline \multicolumn{4}{|l|}{ evita ficar doente } \\
\hline \multicolumn{4}{|c|}{$\begin{array}{l}\text { evita problemas de coluna, respiratórios } \\
\text { e/ou cardiovasculares }\end{array}$} \\
\hline \multicolumn{4}{|l|}{ gosto de competir } \\
\hline \multicolumn{4}{|c|}{ gosto de fazer atividades físicas individuais } \\
\hline \multicolumn{4}{|c|}{ gosto de fazer novas amizades } \\
\hline \multicolumn{4}{|l|}{ gosto do(a) meu(minha) professor(a) } \\
\hline \multicolumn{4}{|l|}{ me dá muita disposição } \\
\hline \multicolumn{4}{|l|}{ me dá satisfação } \\
\hline \multicolumn{4}{|l|}{ me diverte } \\
\hline \multicolumn{4}{|l|}{ me faz sentir bem } \\
\hline \multicolumn{4}{|l|}{ melhora a minha condição física } \\
\hline \multicolumn{4}{|c|}{$\begin{array}{l}\text { o horário da aula não interfere nos meus } \\
\text { outros compromissos }\end{array}$} \\
\hline \multicolumn{4}{|c|}{ o local é muito bonito e agradável } \\
\hline \multicolumn{4}{|c|}{$\begin{array}{l}\text { o local que eu pratico natação é perto da } \\
\text { minha casa }\end{array}$} \\
\hline \multicolumn{4}{|c|}{$\begin{array}{l}\text { o local que eu pratico natação possui } \\
\text { facilidades de acesso }\end{array}$} \\
\hline \multicolumn{4}{|c|}{$\begin{array}{l}\text { o meu professor de educação física } \\
\text { me incentiva }\end{array}$} \\
\hline \multicolumn{4}{|l|}{$\begin{array}{l}\text { o professor está sempre criando e } \\
\text { ensinando algo diferente }\end{array}$} \\
\hline o valor da mensalidade não é muit & & & \\
\hline o(a) professor(a) é atencioso(a) co & & & \\
\hline o(a) professor(a) é muito paciente & & & \\
\hline os meus amigos me incentivam & & & \\
\hline $\begin{array}{l}\text { posso vencer e ganhar medalhas, } \\
\text { e outras recompensas }\end{array}$ & & & \\
\hline preciso tratar de uma doença que & & & \\
\hline preenche meu tempo de forma pr & & & \\
\hline $\begin{array}{l}\text { quero participar de campeonatos } \\
\text { Federação de Natação }\end{array}$ & & & \\
\hline deixa o corpo bonito & & & \\
\hline $\begin{array}{l}\text { sou muito elogiado por praticar es } \\
\text { atividade física }\end{array}$ & & & \\
\hline tem muita gente legal praticando & & & \\
\hline tenho desconto na mensalidade & & & \\
\hline $\begin{array}{l}\text { tenho que me recuperar de uma } \\
\text { lesão/doença }\end{array}$ & & & \\
\hline
\end{tabular}

Caso haja necessidade, o espaço a seguir é para incluir quaisquer outros motivos não contemplados na listagem anterior que você considera 'muito importante' para justificar o porquê você continua praticando natação: 


\section{REFERÊNCIAS}

1. American College of Sports Medicine. ACSM's guidellines for exercise testing and prescription. $7^{\text {th }}$ ed. Baltimore: Willians \& Wilkins; 2006.

2. US Department of Health and Human Services. Physical activity and health: a report of the surgeon general. Atlanta, GA: US Department of Health and Human Services, Centers for Disease Control and Prevention, National Center for Chronic Disease prevention and Health Promotion; 1996.

3. Troiano RP, Briefel RR, Caroll MD, Bialostosky K. Energy and fat intakes of children and adolescents in the United States: data from the national health and nutrition examination surveys. Am J Clin Nutr. 2000;2:1343-53.

4. Janz KF, Burns TL, Torner JC, Levy SM, Paulos R, Willing MC, et al. Physical activity and bone measures in young children: the lowa bone development study. Pediatrics. 2001;107:1387-93.

5. Araújo CGS, Bar-or O. Asma e exercício. In: Becker B, Cole AJ, editores. Terapia aquática moderna. São Paulo: Manole; 2001. p. 137-44.

6. Rosimini $\mathrm{C}$. Benefits of swim training for children and adolescents with asthma. J Am Acad Nurse Pract. 2003;15:247-52.

7. Farinatti PTV, Ferreira MS. Saúde, promoção da saúde e educação física: concei tos, princípios e aplicações. Rio de Janeiro: EdUERJ; 2006.

8. Telama R, Yang X, Laakso L, Viikari J. Physical activity in childhood and adolescence as predictor of physical activity in young adulthood. Am J Prev Med. 1997; 13:317-23.

9. Trudeau F, Laurencelle L, Tremblay J, Rajic M, Shephard RJ. Daily primary school physical education: effects on physical activity during adult life. Med Sci Sports Exerc. 1998:31:111-7.

10. Nahas MV. Atividade física, saúde e qualidade de vida: conceitos e sugestões para um estilo de vida ativo. Londrina: Midiograf; 2001.

11. Farinatti PTV, Ferreira MS. Educação física escolar, promoção da saúde e aptidão física: prevenção primária ou modelo de capacitação? Motus Corporis. 2002;9:75101.

12. Buss PM. Promoção da saúde e qualidade de vida. Ciên Saúde Coletiva. 2000;5: 163-77.

13. Myers RE, Roth DL. Perceived benefits of and barriers to exercise and stage of exercise adoption in young adults. Health Psychol. 1997;16:277-83.

14. Resende H, Votre S, Pace M, Fontes P. Analysis of thematic and methodological tendencies in scientific production about swimming. The FIEP Bulletin. 2004;74: 168-72.

15. Mota J, Sallis JC. Actividade física e saúde: factores de influência da actividade física nas crianças e nos adolescentes. Porto: Campo das Letras; 2002.

16. Sallis JF, Prochaska JJ, Taylor WC. A review of correlates of physical activity of children and adolescents. Med Sci Sports Exerc. 2000;32:963-75.

17. Gill D, Gross J, Huddleston S. Participations motivation in youth sports. International Journal of Sport Psychology. 1983;14:1-14.
18. Ryan R, Fredrick C, Lepes D, Rubio N, Sheldon K. Intrinsic motivation and exercise adherence. Internacional Journal of Sport Psychology. 1997;28:335-54.

19. Alves J, Lourenço A. Tradução e adaptação do Questionário de Motivação para o Exercício. Revista Científica da Escola Superior de Desporto de Rio Maior. 2003; 2:3-11.

20. Gliem JA, Gliem RR. Calculating, interpreting, and reporting Cronbach's alpha reliability coefficient for likert-type scales. In: Midwest Research-to-Practice Conference in Adult, Continuing and Community Education. Columbus; 2003. p. 82 8.

21. Lovisolo H. Normas, utilidades e gostos na educação. In: Votre SJ, Costa VLMC editores. Cultura, atividade corporal e esporte. Rio de Janeiro: Editora Gama FiIho; 1995. p. 213-31.

22. Santos RS, Barcelos LS. Interesses sociais e esportivos do lazer, a visão da equipe masculina de handebol de Catanduva. In: Congresso Científico Latino-Americano de Educação Física da Unimep. Piracicaba; 2004. p. 1201.

23. Botti M, Vieira LF. Ginástica rítmica - análise dos fatores motivadores e estressantes da seleção brasileira juvenil. In: Congresso Científico Latino-Americano de Educação Física da Unimep. Piracicaba; 2004. p. 914.

24. Centers for Disease Control and Prevention. Guidelines for school and community programs to promote lifelong physical activity young people. Morb Mortal Wkly Rep. 1997;46:1-36

25. Costa RM. Razões e motivos para prática de natação de adultos em academias na cidade de Limeira-SP. Motriz. 1999:5:116.

26. Benassi S, Shigunov V. Os motivos sociais e a sua relação com a prática da natação. Rev Bras Ciên Esporte. 1993;15:134.

27. Vieira V, Ferreira MS. Perfil de praticantes de atividade física na pista do Maracanã. Ação e Movimento. 2004;1:81-90.

28. Cid LF. Alterações dos motivos para a prática desportiva das crianças e jovens. Lecturas: Educación Física y Deportes, Revista Digital 2002;55:8. Disponível em: http://www.efdeportes.com

29. Instituto Brasileiro de Geografia e Estatística. Pesquisa sobre padrões de vida 1996-1997. Rio de Janeiro: IBGE; 1999.

30. Scalon RM. Fatores motivacionais que influem na aderência e no abandono dos programas de iniciação desportiva pela criança. Dissertação de Mestrado. Porto Alegre: UFRGS; 1998.

31. Castro MS. Motivos que influenciam a adesão à prática de exercícios físicos nos programas oferecidos pelo Serviço Social do Comércio (SESC), no Distrito Federal. Dissertação de Mestrado. Rio de Janeiro: UGF; 2006.

32. Andreotti MC. Fatores que influenciam a adesão de idosos a um programa de educação física supervisionado Dissertação de Mestrado. São Paulo: USP; 2001. 